\title{
Folic acid supplementation, dietary folate intake during pregnancy and risk for spontaneous preterm delivery: a prospective observational cohort study
}

Verena Sengpiel ${ }^{1 *}$, Jonas Bacelis ${ }^{1}$, Ronny Myhre ${ }^{2}$, Solveig Myking ${ }^{2}$, Aase Serine Devold Pay ${ }^{3}$, Margaretha Haugen ${ }^{4}$, Anne-Lise Brantsæter ${ }^{4}$, Helle Margrete Meltzer ${ }^{4}$, Roy Miodini Nilsen ${ }^{5}$, Per Magnus ${ }^{6}$, Stein Emil Vollset ${ }^{7}$,

Staffan Nilsson ${ }^{8}$ and Bo Jacobsson ${ }^{1,2}$

\begin{abstract}
Background: Health authorities in numerous countries recommend periconceptional folic acid supplementation to prevent neural tube defects. The objective of this study was to examine the association of dietary folate intake and folic acid supplementation during different periods of pregnancy with the risk of spontaneous preterm delivery (PTD).

Methods: The Norwegian Mother and Child Cohort Study is a population-based prospective cohort study. A total of 66,014 women with singleton pregnancies resulting in live births in 2002-2009 were included. Folic acid supplementation was self-reported from 26 weeks before pregnancy until pregnancy week 24 . At gestational week 22 , the women completed a food frequency questionnaire, which allowed the calculation of their average total folate intake from foods and supplements for the first 4-5 months of pregnancy. Spontaneous PTD was defined as the spontaneous onset of delivery between weeks $22^{+0}$ and $36^{+6}(n=1,755)$.

Results: The median total folate intake was $313 \mu \mathrm{g} / \mathrm{d}$ (interquartile range IQR 167-558) in the overall population and $530 \mathrm{\mu g} / \mathrm{d}$ (IQR 355-636) in the supplement users. Eighty-five percent reported any folic acid supplementation from $<8$ weeks before to 24 weeks after conception while only $44 \%$ initiated folic acid supplementation before pregnancy. Cox regression analysis showed that the amount of dietary folate intake (hazard ratio HR 1.00; confidence interval 95\% Cl 0.61-1.65) and supplemental folate intake (HR 1.00; Cl 1.00-1.00) was not significantly associated with the risk of PTD. The initiation of folic acid supplementation more than 8 weeks before conception was associated with an increased risk for spontaneous PTD (HR 1.18; Cl 1.05-1.32) compared to no folic acid supplementation preconception. There was no significant association with PTD when supplementation was initiated within 8 weeks preconception (HR 0.99; $\mathrm{Cl} 0.87-1.13$ ). All analyses were adjusted for maternal characteristics and socioeconomic, health and dietary variables.
\end{abstract}

Conclusions: Our findings do not support a protective effect of dietary folate intake or folic acid supplementation on spontaneous PTD. Preconceptional folic acid supplementation starting more than 8 weeks before conception was associated with an increased risk of spontaneous PTD. These results require further investigation before discussing an expansion of folic acid supplementation guidelines.

Keywords: Pregnancy, Preterm delivery, Preterm birth, Gestational length, Folate, Folic acid supplementation

\footnotetext{
* Correspondence: verena.sengpiel@obgyn.gu.se

'Department of Obstetrics and Gynaecology, Sahlgrenska Academy,

Sahlgrenska University Hospital/Östra, Göteborg SE-416 85, Sweden

Full list of author information is available at the end of the article
} 


\section{Background}

Folate is a B-vitamin essential for one-carbon metabolism and takes part in amino acid metabolism as well as DNA synthesis, repair and methylation [1,2]. Women are especially susceptible to folate deficiency during pregnancy, which is a period of rapid fetal growth, organ differentiation and high rates of cell division [1,3,4]. Since the 1950s, folic acid supplementation has been known to prevent megaloblastic anemia during pregnancy [5]. In the 1990s, large randomized trials demonstrated that periconceptional folic acid supplementation can prevent neural tube defects (NTDs) in the newborn infant [6-8]. Today, national health authorities in many countries recommend periconceptional folic acid supplementation, and some countries have introduced mandatory folate fortification of foods $[1,3,4,9,10]$. In Norway, folic acid supplementation of $400 \mu \mathrm{g} / \mathrm{d}$ is recommended from the time of planning a pregnancy to gestational week $12[2,11]$, as is a daily folate intake of $500 \mu \mathrm{g} / \mathrm{d}$. This is in line with the Nordic Nutrition Recommendations [2].

Maternal folate status has also been associated with other adverse pregnancy outcomes such as preeclampsia, malformations such as orofacial clefts, spontaneous abortion, fetal death, fetal growth restriction and preterm delivery (PTD), although these results still remain inconclusive [1].

PTD, defined by the World Health Organization (WHO) as birth occurring before 37 weeks of gestation, is considered a major global health problem and is strongly associated with neonatal mortality as well as short- and long-term morbidity [12-14]. Spontaneous PTD is a common, complex condition with a prevalence of approximately $7 \%$ in the Norwegian population [15]. However, the effect of any single environmental factor is difficult to measure without large-scale studies [15]. Modern obstetrics are still not able to predict, prevent or treat PTD [16]. Progesterone substitution, the only promising intervention identified to date, has been shown to reduce the chance of spontaneous PTD in high-risk pregnancies, but such cases account for only a small proportion of all pregnancies $[17,18]$.

In the past decade, some observational studies have found that folic acid supplementation reduces the risk of PTD [19-22]. In some studies, this effect has been documented with an extended folic acid supplementation scheme or dosage compared with schemes based on NTD prevention, e.g., preconceptional folic acid supplementation for one year or longer [21] or third-trimester folic acid supplementation [22]. A study based on the previous Cochrane review and data of one of the largest randomized controlled trials (RCT), a recent meta-analysis of all published RCTs, as well as the recent Cochrane review based on 3 controlled trials could not confirm any effect of the maternal folate status on the gestational length or the risk of spontaneous PTD [23-25]. The comparability and generalizability of these earlier studies, which focused on the association of folate status and folic acid supplementation with pregnancy outcome, is limited because folic acid supplementation was assessed without considering other folate sources, the study populations had different levels of dietary folate intake, inadequate sample sizes, limited adjustment for important confounders, and/or retrospective study designs with folate data collection only after delivery $[1,4]$. Although PTD is a heterogeneous pregnancy outcome with different etiologies (early vs. late or iatrogenic vs. spontaneous), previous studies have mostly treated PTD as one entity, obscuring the differences in risk among PTD subtypes [26,27].

The Norwegian Mother and Child Cohort Study (MoBa) can meet a number of these challenges in study design, a requirement for addressing the inconsistencies in the field. MoBa includes more than 106,000 pregnancies, enabling the investigation of common complex pregnancy outcomes such as PTD. A detailed prospective assessment of folic acid supplementation starting from 6 months before conception throughout pregnancy, data regarding dietary folate intake and comprehensive information about lifestyle habits, health and socioeconomic status provide a unique opportunity to study the association between folate intake and PTD. For example, the effect of folic acid supplementation can be compared between women with low and high dietary folate intakes. By taking into account the amount of dietary folate and folic acid supplementation during different periods of pregnancy, it might be possible to define the folic acid supplementation scheme most likely to affect PTD risk.

The aim of this study was to examine the association of maternal folate intake from both supplemental and dietary sources with the risk of spontaneous PTD, with sub-analyses of early and late spontaneous PTD. The association of folic acid supplementation with PTD was studied in a stratified sample of women with low and high dietary folate intakes $(</ \geq 170 \mu \mathrm{g} / \mathrm{d})$.

\section{Methods}

\section{Study population}

The dataset is part of the MoBa cohort, initiated by and maintained at the Norwegian Institute of Public Health [15]. In brief, MoBa is a nation-wide pregnancy cohort that has included more than 106,000 pregnancies in the years from 1999 to 2009. The women were recruited through a postal invitation in connection with a routine ultrasound examination offered to all pregnant women in Norway approximately 17 weeks of gestation. Overall, $38.5 \%$ of the invited women participated. They were asked to fill in questionnaires focused on overall health 
status, lifestyle behavior and diet at gestational weeks 15-17 (Q1) and 30 (Q3). At week 22, they completed a food frequency questionnaire (FFQ). All questionnaires are available from the homepage of the Norwegian Institute of Public Health [28]. The present study used data from version 6 of the quality-assured data files made available for research in 2011. The MoBa database is linked to pregnancy and birth records from the Medical Birth Registry of Norway (MBRN) [29]. Informed written consent was obtained from each participant. The Regional Committee for Medical Research and the Norwegian Data Inspectorate approved the study.

Of 106,707 pregnancies included in the MoBa version $6,103,921$ pregnancies resulted in live-born singletons. Complete data for all 3 questionnaires including information about folate intake were available for 81,329 pregnancies. Women reporting improbable energy intakes of $<4.5 \mathrm{MJ}$ or $>20 \mathrm{MJ}$ were excluded [30], leaving 80,056 pregnancies. After exclusion of women with prepregnancy diabetes mellitus, chronic hypertension, chronic kidney disease, epilepsia, rheumatoid arthritis and those that underwent in-vitro fertilization, 76,298 pregnancies were included in the study. Pregnancies with a gestational length of $<22^{+0}$ or $>42^{+6}$ weeks were excluded from further analysis, leaving 75,873 remaining. If a woman participated for more than one pregnancy, only her first pregnancy enrolled was included, leaving 66,014 pregnancies for analyses.

\section{Outcome}

The gestational age in days was determined with a second-trimester ultrasound in $98.4 \%$ of the pregnancies and was based on the last menstrual period in the remaining cases. Spontaneous PTD was defined as birth after preterm labor or pre-labor rupture of the membranes between $22^{+0}$ and $36^{+6}$ weeks. To distinguish between early and late spontaneous PTDs, we used the following gestational time-windows: early $\left(22^{+0}-33^{+6}\right)$ and late $\left(34^{+0}-36^{+6}\right)$ PTD.

\section{Exposure}

\section{Amount of folate intake}

The amount of folate intake was calculated from the MoBa FFQ, a semi-quantitative questionnaire designed to yield information regarding the dietary habits and intake of dietary supplements during the first 5 months of pregnancy. The questionnaire data were read optically, and the nutrient and energy intakes were calculated using FoodCalc [31] and the Norwegian Food Composition Table [32]. For the calculation of nutrients in the dietary supplements, an Access database containing the nutrient values of more than 1,000 dietary supplements was created and continuously updated using Microsoft Office 2003 software. Dietary supplements commonly sold in Norway were registered based on information provided by the respective manufacturer, whereas nutritional information concerning dietary supplements bought from the Internet or abroad were obtained from the manufacturer's or supplier's homepage. A data program connected to the Access database read all food supplements recorded by the MoBa participants. The process of extracting dietary and supplement data is described in detail elsewhere $[33,34]$.

Dietary folate was defined as $60 \%$ of the reported folate intake from foods, as only approximately $60 \%$ may be biologically accessible in comparison to that from the synthetic folic acid in supplements $[1,3]$. The total folate intake was thus calculated as supplemental folic acid $+0.6 \times$ folate intake from foods.

The daily folate intake was also categorized into 4 groups: $<170 \mu \mathrm{g} / \mathrm{d}$ (corresponding to the earlier WHO recommendation for all women to prevent anemia $[10,35]$ ), $170-500 \mu \mathrm{g} / \mathrm{d}$ (corresponding to the current Nordic Nutrition Recommendations for pregnant women for the prevention of NTDs [2]), 500-1000 $\mu \mathrm{g} / \mathrm{d}$ (corresponding to the tolerable upper limit for folic acid [2]) and $>1000 \mu \mathrm{g} / \mathrm{d}$.

\section{Timing of folic acid supplementation}

The women reported their folic acid supplement use from 26 weeks before conception until gestational week 24 in 4-week intervals, including the frequency of supplementation. A woman was defined as a folic acid supplement user if she reported any use of folic acid containing supplements for more than once a week in a registered 4-week period. Folic acid may be consumed either in the form of a folic acid supplement alone or as part of multivitamins. The most commonly used folic acid supplements for pregnant women in Norway contain $400 \mu \mathrm{g}$ of folic acid, while the most commonly used multivitamin supplements contain $200 \mu \mathrm{g}$ of folic acid. For this study, the start of folic acid supplementation was categorized as start during 26-9 weeks before conception, start during 8-0 weeks before conception, and no preconceptional folic acid supplementation.

\section{Covariates}

Covariates were chosen a priori based on the available literature. Information regarding the maternal age at delivery as well as the child's sex is available from the MBRN. Parity was based on data from both the MoBa and MBRN and based on the number of previous pregnancies of $\geq 22^{+0}$ weeks' duration. Marital status was defined as either married/cohabitant or not. The selfreported pre-pregnancy heights and weights were used to calculate the pre-pregnancy body mass index (BMI) and were grouped according to the WHO classification as underweight $\left(<18.5 \mathrm{~kg} / \mathrm{m}^{2}\right)$, normal $\left(18.5-24.9 \mathrm{~kg} / \mathrm{m}^{2}\right)$, overweight $\left(25.0-29.9 \mathrm{~kg} / \mathrm{m}^{2}\right)$ and obese $\left(\geq 30.0 \mathrm{~kg} / \mathrm{m}^{2}\right)$. 
Maternal education was categorized as $\leq 12 \mathrm{y}, 13-16 \mathrm{y}$ and $\geq 17 \mathrm{y}$. The history of previous PTD before $37^{+0}$ weeks of gestation, and the history of spontaneous abortion, as registered in the MBRN, were taken into account as dichotomous variables in regression models. Women reported smoking habits during pregnancy in Q1 and were categorized as non-smokers, occasional or daily smokers. The alcohol intake from different sources was self-reported in the FFQ (glasses/d, week or month) and calculated as $\mathrm{g} / \mathrm{d}$. The household income was classified as both the participant and her partner having $<300,000$ Norwegian Kroner $(\mathrm{NOK}) / \mathrm{y}$, as either the participant or her partner having $\geq 300,000 \mathrm{NOK} / \mathrm{y}$ or as the participant and her partner both having $\geq 300,000 \mathrm{NOK} / \mathrm{y}$. Vitamin A supplementation was registered and categorized in the same manner as described for folic acid. These variables were used as a proxy for multivitamin supplementation, as there are no products on the Norwegian market containing vitamin A alone, and vitamin A is part of all common multivitamin preparations. In MoBa more than $99 \%$ of the participants are of Caucasian ethnicity; hence, ethnicity was not a relevant confounder.

\section{Statistical methods}

All statistical analyses were performed using IBM SPSS Statistics 22 and R 2.13.1 software. Total dietary folate intake from foods and supplements (median (IQR)) in relation to the maternal characteristics was studied with the Kruskal-Wallis test. The start of folic acid supplementation in relation to the maternal characteristics was studied with Pearson's chi-squared test. The association of total dietary folate intake and spontaneous PTD was estimated as a hazard ratio (HR) with a $95 \%$ confidence interval (CI) by using Cox regression both in an unadjusted model and adjusted for the above-mentioned covariates. In these models, the event was defined as a spontaneous PTD; all iatrogenic deliveries and deliveries after the preterm $\left(\geq 37^{+0}\right.$ weeks $)$ or early preterm $\left(\geq 34^{+0}\right.$ weeks) period were censored. The proportional hazards assumption was investigated by testing and inspecting scaled Schoenfeld residuals using R function cox.zph [36]. Statistical significance was assumed for 2sided $\mathrm{p}$-values of $<0.05$.

\section{Results}

\section{Folate intake and folic acid supplementation in the study population}

The median total dietary folate intake during the first five months of pregnancy and start of folic acid supplementation according to maternal characteristics are presented in Table 1. Dietary folate intake was highest in women aged 25-29 years, in women who did not smoke, had low or normal BMI $\left(18.5-24.9 \mathrm{~kg} / \mathrm{m}^{2}\right)$, who were having their first child, were married/cohabitant, who had higher education levels and family incomes. Women having experienced PTD had significantly lower total folate intakes. While women with a history of spontaneous abortion had more often started folic acid supplementation early, no comparable pattern in women with a history of PTD was found (Table 1).

Figure 1 illustrates the pattern of folic acid supplementation in the study population compared to vitamin A supplementation (as a proxy for multivitamin consumption) over the course of pregnancy. $85 \%$ of all women in the study reported folic acid supplementation at some point before and/or during pregnancy (Figure 1). While 44\% initiated folic acid supplementation prior to conception, nearly $77 \%$ used supplements containing folic acid in the first trimester with decreasing use towards the end of pregnancy. At the same time, vitamin A supplementation was much more stable over the whole length of the pregnancy. The amount of folic acid supplementation varied considerably, with only 2 women consuming folic acid amounts of $>5000 \mu \mathrm{g} / \mathrm{d}, 610$ consuming $>1000 \mu \mathrm{g} / \mathrm{d}(1 \%), 6,834$ consuming $>500 \mu \mathrm{g} / \mathrm{d}$ (10\%), 10,681 consuming $>400 \mu \mathrm{g} / \mathrm{d}(16 \%), 27,183$ consuming $>200 \mu \mathrm{g} / \mathrm{d}(41 \%)$ and 34,234 consuming $>100 \mu \mathrm{g} / \mathrm{d}$ (52\%). Among supplement users, the median daily folic acid supplementation was $400 \mu \mathrm{g} / \mathrm{d}$ (interquartile range IQR 200-429). As presented in Table 2, folic acid from supplements was the main folate source in supplement users, while the main source was dietary folate in the whole population. There is no mandatory folate fortification of foods in Norway, and only $3 \%(n=1,946$, not adjusted for bioavailability) of the study population reached the Nordic Nutrition Recommendation of $500 \mu \mathrm{g} / \mathrm{d}$ with their dietary folate intake. Of the study participants, $44 \%$ ( $n=28,959$, not adjusted for bioavailability) achieved the recommended levels with their total folate intake.

\section{Folate intake from different sources and risk for spontaneous PTD}

The median gestational age in this study population was 281 days (IQR 274-287), with 2,906 (4\%) cases of PTD and 1,755 cases of spontaneous PTD (2.7\%). Of these, 334 babies were delivered before $34^{+0}$ weeks of gestation (0.5\%). Thus the overall PTD rate in our study population is approximately half of the PTD rate in the general Norwegian population as we excluded risk-pregnancies due to maternal disease as well as multiple gestations and intrauterine death.

There was no significant association between the amount of folate intake from the diet or supplements with the risk of spontaneous PTD (Table 3). As 95\% CIs were very narrow, we performed the same analysis in deciles of total folate intake as well with a categorized variable according to deciles of total folate intake with no change of results (data not shown). Likewise, no association was found when the total folate intake was 
Table 1 Folate variables and maternal characteristics

\begin{tabular}{|c|c|c|c|c|c|c|c|c|c|c|c|c|c|}
\hline \multirow{3}{*}{$\overline{T o t a l}$} & & \multirow[b]{2}{*}{$\mathrm{n}$} & \multirow{3}{*}{$\begin{array}{l}(\%) \\
(100)\end{array}$} & \multicolumn{3}{|c|}{ Total folate intake $(\mu \mathrm{g} / \mathrm{d})$} & \multicolumn{7}{|c|}{ Initiation of preconceptional folic acid supplementation, $\mathrm{n}(\%)$} \\
\hline & & & & \multicolumn{2}{|c|}{ Median (IQR) } & \multirow[t]{2}{*}{$p^{1}$} & \multicolumn{2}{|c|}{$>8 w$} & \multicolumn{2}{|l|}{$0-8 w$} & \multicolumn{2}{|l|}{ No } & \multirow[t]{2}{*}{$p^{2}$} \\
\hline & & 66014 & & 313 & $(167-558)$ & & 16023 & (24) & 12877 & (20) & 37114 & (56) & \\
\hline & $<25$ & 7561 & (12) & 258 & $(154-528)$ & & 849 & (11) & 942 & (13) & 5770 & (76) & \\
\hline \multirow[t]{3}{*}{ Maternal age in years } & $25-29$ & 22672 & (34) & 324 & $(170-562)$ & $<0.0001$ & 5121 & (23) & 4821 & (21) & 12730 & (56) & $<0.0001$ \\
\hline & $30-34$ & 27993 & $(42)$ & 319 & $(168-562)$ & & 7726 & (28) & 5894 & (21) & 14373 & (51) & \\
\hline & $>34$ & 7788 & (12) & 315 & $(170-562)$ & & 2327 & (30) & 1220 & (16) & 4241 & (55) & \\
\hline \multirow[t]{7}{*}{ Pre-pregnancy BMl in $\mathrm{kg} / \mathrm{m}^{2}$} & $<18.5$ & $19 \backslash 31$ & (3) & 343 & $(179-575)$ & & 432 & (22) & 351 & (18) & 1148 & (60) & \\
\hline & $18.5-24.9$ & 42611 & (65) & 328 & $(173-566)$ & $<0.0001$ & 10773 & (25) & 8637 & (20) & 23201 & (54) & $<0.0001$ \\
\hline & $25-30$ & 13839 & (21) & 289 & $(160-548)$ & & 3228 & (23) & 2651 & (19) & 7960 & (58) & \\
\hline & $\geq 30$ & 5970 & (9) & 268 & $(151-533)$ & & 1305 & (22) & 953 & (16) & 3712 & (62) & \\
\hline & Missing & 1663 & (3) & 250 & $(156-517)$ & & 285 & (17) & 285 & (17) & 1093 & (66) & \\
\hline & 0 & 34825 & (53) & 355 & $(180-580)$ & & 9324 & (27) & 6480 & (19) & 19021 & (55) & \\
\hline & 1 & 20028 & (30) & 281 & $(159-545)$ & $<0.0001$ & 4528 & (23) & 4531 & (23) & 10969 & (55) & $<0.0001$ \\
\hline \multirow[t]{3}{*}{ Parity } & 2 & 9005 & (14) & 245 & $(156-517)$ & & 1787 & (20) & 1570 & (17) & 5648 & (63) & \\
\hline & $3+$ & 2101 & (3) & 224 & $(149-451)$ & & 370 & (18) & 285 & (14) & 1446 & (69) & \\
\hline & Missing & 55 & $(0.1)$ & 353 & $(166-566)$ & & 14 & (26) & 11 & (20) & 30 & (55) & \\
\hline \multirow[t]{2}{*}{ Marita status } & Yes & 63518 & (96) & 315 & $(168-559)$ & $<0.0001$ & 15714 & (25) & 12661 & (20) & 35143 & (55) & $<0.0001$ \\
\hline & No & 2496 & (4) & 266 & $(158-531)$ & & 309 & (12) & 216 & (9) & 1971 & (79) & \\
\hline \multirow[t]{4}{*}{ Maternal education in years } & $<13$ & 20198 & (31) & 244 & $(150-515)$ & & 3263 & (16) & 2886 & (14) & 14049 & (70) & \\
\hline & $13-16$ & 27606 & (42) & 338 & $(172-567)$ & $<0.0001$ & 7118 & (26) & 5849 & (21) & 14639 & (53) & $<0.0001$ \\
\hline & $>16$ & 16838 & (26) & 374 & $(187-581)$ & & 5340 & (32) & 3916 & (23) & 7582 & (45) & \\
\hline & Missing & 1372 & (2) & 283 & $(161-550)$ & & 302 & (22) & 226 & (17) & 844 & (62) & \\
\hline \multirow{3}{*}{$\begin{array}{l}\text { History of preterm } \\
\text { delivery }\end{array}$} & No & 63698 & (97) & 314 & $(168-559)$ & $<0.0001$ & 15510 & (24) & 12411 & (20) & 35777 & (56) & 0.047 \\
\hline & Yes & 2205 & (3) & 276 & $(158-539)$ & & 487 & (22) & 435 & (20) & 1283 & (58) & \\
\hline & Missing & 111 & $(0.2)$ & 297 & $(175-560)$ & & 26 & (23) & 31 & (28) & 54 & (49) & \\
\hline \multirow[t]{4}{*}{ History of abortion } & No & 45164 & (68) & 315 & $(168-559)$ & 0.15 & 10262 & (23) & 8930 & (20) & 25972 & (58) & $<0.0001$ \\
\hline & Yes & 12418 & (19) & 308 & $(166-558)$ & & 3932 & (32) & 2296 & (19) & 6190 & (50) & \\
\hline & Missing & 8432 & (13) & 308 & $(165-557)$ & & 1829 & (22) & 1651 & (20) & 4952 & (59) & \\
\hline & Never & 60452 & (92) & 322 & $(170-563)$ & & 15339 & (25) & 12271 & (20) & 32842 & (54) & \\
\hline \multirow[t]{3}{*}{ Smoking habits } & Occasionally & 1741 & (3) & 261 & $(158-511)$ & $<0.0001$ & 243 & (14) & 226 & (13) & 1272 & (73) & $<0.0001$ \\
\hline & Daily & 3449 & (5) & 217 & $(141-485)$ & & 378 & (11) & 316 & (9) & 2755 & (80) & \\
\hline & Missing & 372 & (0.6) & 236 & $(148-500)$ & & 63 & (17) & 64 & (17) & 245 & (66) & \\
\hline \multirow{3}{*}{$\begin{array}{l}\text { Alcohol consumption } \\
\text { in units/week }\end{array}$} & No alcohol & 58659 & (89) & 314 & $(167-559)$ & & 14448 & (25) & 11528 & (20) & 32683 & (56) & \\
\hline & $<0.5$ & 6155 & (9) & 311 & $(170-556)$ & 0.21 & 1326 & (22) & 1164 & (19) & 3665 & (60) & $<0.0001$ \\
\hline & $\geq 0.5$ & 1200 & (2) & 286 & $(167-531)$ & & 249 & (21) & 185 & (15) & 766 & (64) & \\
\hline Partners with & 0 & 18364 & (28) & 279 & $(161-540)$ & $<0.0001$ & 3176 & (17) & 2904 & (16) & 12284 & (67) & \\
\hline income of >300,000 & 1 & 27212 & (41) & 309 & $(166-557)$ & & 6460 & (24) & 5451 & (20) & 15301 & (56) & $<0.0001$ \\
\hline & 2 & 18608 & (28) & 360 & $(178-579)$ & & 6130 & (33) & 4247 & (23) & 8231 & (44) & \\
\hline NOK/year & Missing & 1830 & (3) & 264 & $(158-533)$ & & 257 & (14) & 275 & (15) & 1298 & (71) & \\
\hline Baby's sex & Male & 33791 & (51) & 309 & $(166-558)$ & 0.07 & 8190 & (24) & 6525 & (19) & 19076 & (57) & 0.4 \\
\hline & Female & 32223 & (49) & 316 & $(169-559)$ & & 7833 & (24) & 6352 & (20) & 18038 & (56) & \\
\hline Tertiles of energy intake in MJ & 1 & 22005 & (33) & 272 & $(127-525)$ & & 5577 & (25) & 4338 & (20) & 12090 & (55) & \\
\hline & 2 & 22005 & (33) & 317 & $(166-561)$ & $<0.0001$ & 5511 & (25) & 4485 & (20) & 12009 & (55) & $<0.0001$ \\
\hline & 3 & 22004 & (33) & 344 & $(211-600)$ & & 4935 & (22) & 4054 & (18) & 13015 & (59) & \\
\hline
\end{tabular}


categorized according to the former WHO recommendation for women $(>170 \mu \mathrm{g} / \mathrm{d})$, the current Nordic Nutrition Recommendations for pregnant women $(>500 \mu \mathrm{g} / \mathrm{d}$ ) and the tolerable upper limit (for folic acid supplementation: $<1000 \mu \mathrm{g} / \mathrm{d}$ ) (Additional file 1: Table S1). Cox regression for the sub-groups of early and late spontaneous PTD did not reveal any significant associations between the folate intake and pregnancy outcome (not shown). Testing the proportional hazards assumptions revealed a slight misfit for the parity variable. Therefore all analyses were also run with stratified Cox regression using parity as strata. The changes from the unstratified analyses were however marginal and did not change any pattern or results.

\section{Initiation of folic acid supplementation and risk for spontaneous PTD}

The initiation of folic acid supplementation more than 8 weeks preconception was associated with increased risk of spontaneous PTD overall also after adjusting for potential confounders (Table 4 and Additional file 2: Figure S1a; hazard ratio HR 1.19; confidence interval CI 1.05-1.34). The initiation of supplementation more than 8 weeks before conception was significantly associated with early $\left(<34^{+0}\right.$ weeks $)$ but not late spontaneous PTD (Additional file 3: Figure S1b). After stratification for the total dietary folate intake from foods, the initiation of folic acid supplementation more than 8 weeks before conception was significantly associated with an increased risk of spontaneous PTD for those women with low dietary folate intakes (adjusted HR 1.18; 95\% CI 1.05-1.32). The same association was found in the subgroup of early (adjusted HR 1.60; 95\% CI 1.24-2.10) but not late spontaneous PTD (Additional file 4: Table S2).

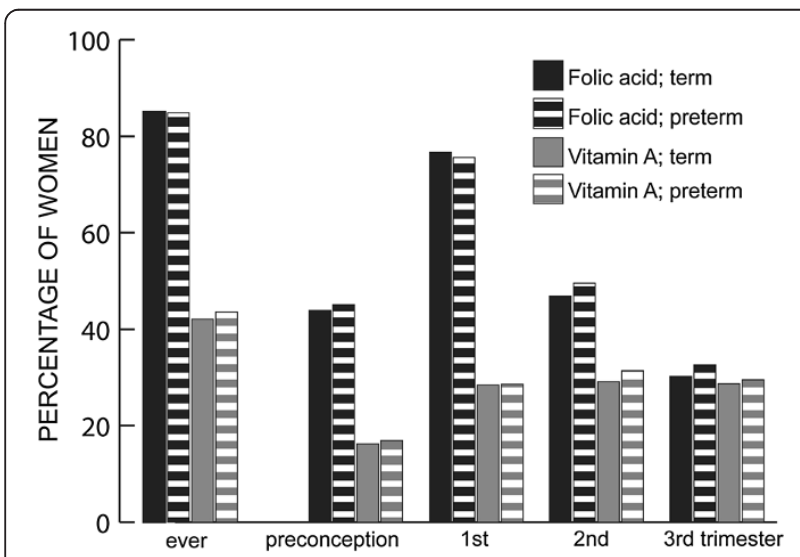

Figure 1 Prevalence of folic acid and vitamin A supplementation during pregnancy. Prevalence of folic acid and vitamin A supplementation during pregnancy (Q1 and Q3 data) in women with spontaneous non-preterm $\left(37^{+0}-42^{+6}\right.$ weeks, $\left.n=51,141\right)$ or preterm delivery $\left(22^{+0}-36^{+6}\right.$ weeks, $\left.n=1,755\right)$ among 66,014 participants in the Norwegian Mother and Child Cohort Study (2002 - 2009).
A history of earlier adverse pregnancy outcome could be a motive for the early initiation of folic acid supplementation in subsequent pregnancies. However, the analysis of the subgroup of women being pregnant the first time ( $\mathrm{n}=25,281,38 \%)$ showed the same overall results for the early initiation of folic acid supplementation ( $\mathrm{n}=$ 815 cases of spontaneous PTD, adjusted HR 1.30; CI 1.10-1.53).

The early initiation of folic acid supplementation could characterize women that planned a pregnancy but did not become pregnant during the first months, thus including a subgroup of sub-fertile women [37]. In MoBa, the women were asked to report the number of months with regular intercourse without contraception before becoming pregnant, and these data were classified as follows: $<1$ month ( $\mathrm{n}=13,128,20 \%), 1-2$ months ( $\mathrm{n}=$ $15,142,23 \%)$ and $>2$ months $(\mathrm{n}=22,702,34 \%)$. Stratification for this variable still showed increased HRs for the early initiation of folic acid supplementation in the subgroup that became pregnant within the first month (adjusted HR 1.58; CI 1.17-2.12), the HRs for the small subgroup with early PTD $(n=68)$ was not significant (adjusted HR 1.78; CI 0.98-3.23).

\section{Timing of folic acid supplementation and risk for spontaneous PTD}

The time of folic acid supplementation was represented by four variables corresponding to the following periods: $26-$ 9 weeks before conception, $0-8$ weeks before conception, first trimester and second trimester. If the Cox regression included all of the confounders and the outcome of spontaneous PTD was analyzed, the prediction of the model improved after introducing all four folic acid supplementation variables $(\mathrm{p}=0.006)$. Folic acid supplement use more than 8 weeks preconception was associated with an increased HR for spontaneous PTD, even after adjusting for the supplementation at all other time points (Table 5).

\section{Discussion}

In this large prospective national birth cohort, we did not find any statistically significant association of the amount of folate intake from the diet or supplements with spontaneous PTD. Folic acid supplementation starting more than 8 weeks before conception was associated with an increased HR for spontaneous PTD.

When interpreting the results, the selection of the study population has to be kept in mind: risk-pregnancies due to maternal disease and multiple gestations have been excluded from the analysis so that we do not know if there is any association of the amount of folate intake from diet or supplements with spontaneous PTD in the excluded high risk pregnancies.

Our results, demonstrating no significant protective effect of the maternal folate intake or folic acid 
Table 2 Folate intake from diet and supplements

\begin{tabular}{|c|c|c|c|c|c|c|}
\hline \multirow[b]{2}{*}{ Folate $(\mu \mathrm{g} / \mathrm{d})$} & \multicolumn{2}{|l|}{ All } & \multicolumn{2}{|c|}{ Spontaneous delivery $37^{+0}-42^{+6}$} & \multicolumn{2}{|c|}{ Spontaneous PTD $22^{+0}-36^{+6}$} \\
\hline & Median & IQR & Median & IQR & Median & IQR \\
\hline All women & $n=66014$ & & $n=51141$ & & $n=1755$ & \\
\hline Diet & 157 & $(126-196)$ & 157 & $(126-196)$ & 157 & $(126-196)$ \\
\hline Supplements & 143 & $(0-400)$ & 143 & $(0-400)$ & 171 & $(0-400)$ \\
\hline Total intake & 313 & $(167-558)$ & 312 & $(167-558)$ & 322 & $(167-568)$ \\
\hline Supplement users & $n=39600$ & & $n=30684$ & & $n=1056$ & \\
\hline Diet & 158 & $(127-197)$ & 158 & $(127-197)$ & 159 & $(128-198)$ \\
\hline Supplements & 400 & $(200-429)$ & 400 & $(200-429)$ & 400 & $(200-457)$ \\
\hline Total intake & 530 & $(355-636)$ & 530 & $(355-634)$ & 541 & (369-651) \\
\hline
\end{tabular}

Folic acid supplementation, dietary and total folate intake during the first half of pregnancy (FFQ data) for all 66,014 participants, as well as in folic acid supplement users $(n=39,600)$, from the Norwegian Mother and Child Cohort Study (2002-2009).

supplementation on the spontaneous PTD risk, support a number of earlier observational studies [38-43] and RCTs $[6,44,45]$. A reanalysis of a previous Cochrane review, and one of the largest RCTs, a recent meta-analysis of all RCTs published to date as well as the most recent Cochrane review based on 3 available trials, showed no association of the maternal folate status with the gestational length or the risk of PTD [23-25]. Extensive supplementation with multivitamins with a major folic acid component was associated with an increased risk of PTD in a study by Alwan et al. [38]. When analyzing data from the US National Birth Defects Study, Shaw et al. found a lower risk of PTD for women starting supplementation during pregnancy as compared to preconceptional supplementation start [43].

However, results are conflicting as summarized in the review by Mantovani et al. [27]. A protective effect of folic acid supplementation was supported by a modest reduction in the PTD rate after the introduction of folate fortification of foods [9]. Some recent observational studies have found that folic acid supplementation reduces the risk of PTD [20-22]. In some cases, this association was found for preconceptional folic acid supplementation for

Table 3 Folate intake from different sources and risk of spontaneous preterm delivery (PTD)

\begin{tabular}{|c|c|c|c|c|c|c|}
\hline \multirow[b]{2}{*}{ Folate $(\mu \mathrm{g} / \mathrm{d})$} & \multicolumn{3}{|c|}{ Unadjusted } & \multicolumn{3}{|c|}{ Adjusted $^{2}$} \\
\hline & $\mathrm{HR}^{1}$ & $(95 \% \mathrm{Cl})$ & $\mathbf{p}$ & $\mathrm{HR}^{1}$ & $(95 \% \mathrm{Cl})$ & $p$ \\
\hline Diet & 1.00 & $(0.61 ; 1.65)$ & 0.61 & 1.00 & $(0.61 ; 1.65)$ & 0.54 \\
\hline Supplements & 1.00 & $(1.00 ; 1.00)$ & 0.25 & 1.00 & $(1.00 ; 1.00)$ & 0.53 \\
\hline Total intake & 1.00 & $(1.00 ; 1.00)$ & 0.22 & 1.00 & $(1.00 ; 1.00)$ & 0.46 \\
\hline
\end{tabular}

Amount of folic acid supplementation, dietary and total folate intake (FFQ data) and hazard ratios for spontaneous PTD $\left(22^{+0}-36^{+6}\right.$ weeks, $\left.\mathrm{n}=1,755\right)$. Cox regression for 66,014 participants in the Norwegian Mother and Child Cohort Study (2002-2009). latrogenic deliveries have been censored in the regression model.

${ }^{1} \mathrm{HR}$ per $500 \mu \mathrm{g}$ extra folate/d.

${ }^{2}$ Cox regression, adjusted for maternal age, prepregnancy BMI, parity, history of PTD and spontaneous abortion, child's sex, smoking habits and alcohol consumption during pregnancy, maternal education, marital status, household income, energy intake. Mutual adjustment for dietary and supplemental folate intake.
1 year or longer [21] or third-trimester folic acid supplementation [22], raising questions about extended supplementation schemes compared to the NTD prevention scheme. Folic acid supplementation more than a 1 year before becoming pregnant is not registered in MoBa, but data for the earliest interval (26-9 weeks before conception) suggest an adverse effect of longtime folic acid supplementation on the risk of spontaneous PTD. Though third trimester folic acid supplementation is registered in $\mathrm{MoBa}$, we chose to not include third trimester supplementation as the early PTDs already have occurred at different time points during this period, so that we were not able to retrace the findings by Czeizel et al. [22].

One possible explanation for these conflicting results could be the dosage of folic acid. While most of the studies finding an association with gestational length or PTD were based on high doses of folic acid $(\geq 5000 \mu \mathrm{g} / \mathrm{d}$ $[20,22,46], \geq 2500 \mu \mathrm{g} / \mathrm{d}[22,47]$ and $\geq 500 \mu \mathrm{g} / \mathrm{d}[48-50])$, only 2 women in our study population consumed as much as $5000 \mu \mathrm{g} / \mathrm{d}$ of supplemental folic acid, while only $10 \%$ consumed $>500 \mu \mathrm{g} / \mathrm{d}$ and $16 \%$ consumed $>400 \mu \mathrm{g} /$ d. However, the Hungarian RCT, one of the biggest performed so far, did not find any effect of a high dosage of $800 \mu \mathrm{g} / \mathrm{d}$ of periconceptional folic acid supplementation on PTD [6]. Unfortunately, the folic acid dosage was not indicated in all of the studies [21,37].

The assessment of folate intake from supplementation alone or when studying populations with different dietary folate intakes are additional factors compromising comparability between studies. While recent US studies are performed against the background of mandatory folate fortification of food [21,43], other studies have examined supplementation effects in folate-deficient populations [46]. Few studies have assessed the effects of both dietary folate and folic acid supplementation separately [43] or combined [20,49,51], and adjustments for bioavailability are rare. In this Norwegian study population, only 3\% of the participants reached the Nordic Nutrition Recommendation of $500 \mu \mathrm{g} / \mathrm{d}$ with their dietary folate intake, 
Table 4 Initiation of preconceptional folic acid supplementation and risk of spontaneous preterm delivery (sPTD)

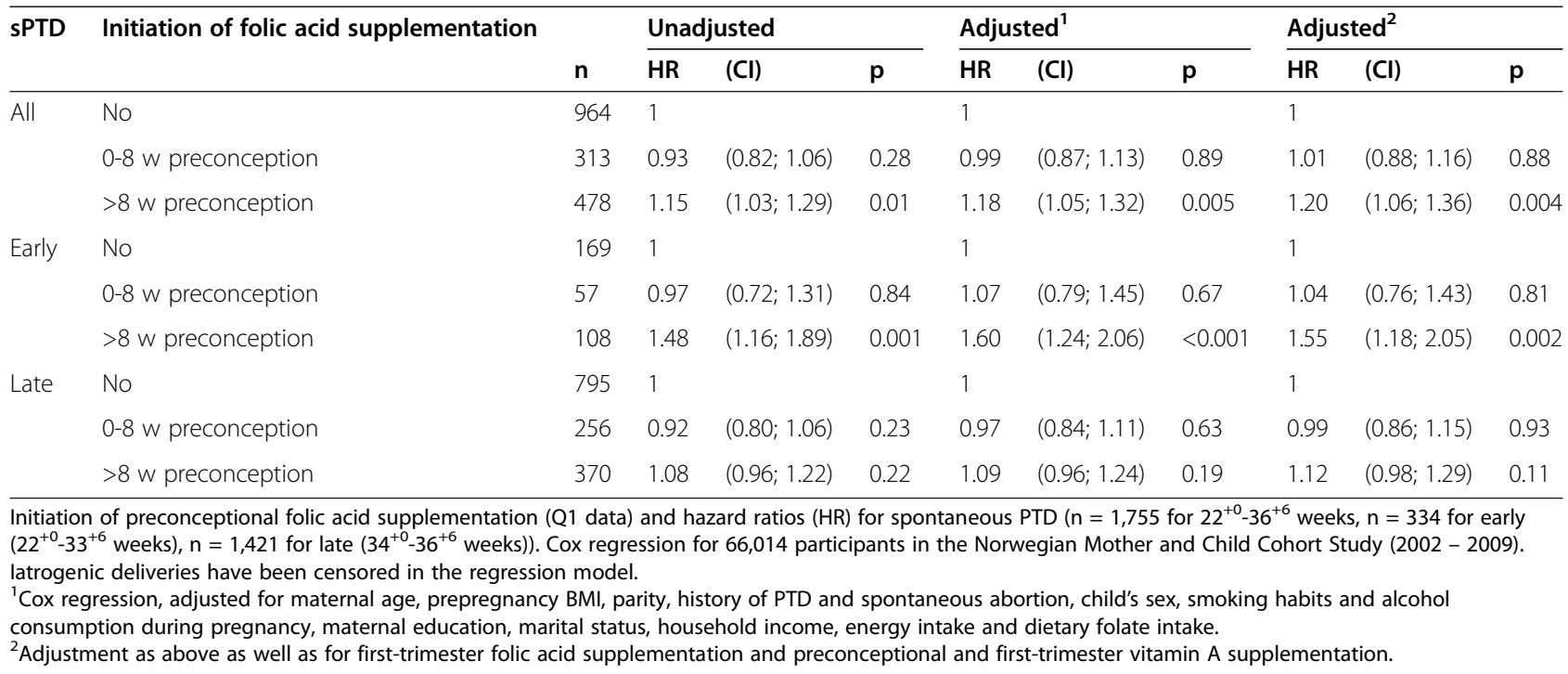

and $44 \%$ of the participants achieved the recommended level with their dietary folate and supplemental folic acid intake. After stratification for dietary folate intake, the early initiation of folic acid supplementation was significantly associated with spontaneous PTD in the subgroup of women with low but not high dietary folate intakes. There were no significant associations between high total folate intakes and PTD risk in the MoBa study population.

In observational studies, confounding is always an issue when assessing the association of a single environmental factor with a complex outcome like PTD. For example, it is well established that women with high levels of education, privileged socioeconomic status and healthier overall diets are more likely to use supplements during pregnancy [52-54] and less likely to experience PTD than women without these characteristics. Some observational studies failed to adjust for these confounders, and the effect attributed to folic acid supplementation might in fact be confounded by overall health and lifestyle behaviors. While the strength of the significance was moderate, the association with the early onset of folic acid supplementation in the current study remained significant even after adjustment for maternal characteristics such as

Table 5 Timing of folic acid supplementation and risk of spontaneous preterm delivery (PTD)

\begin{tabular}{|c|c|c|c|c|c|c|c|c|}
\hline & \multirow[t]{2}{*}{ Time of folic acid supplementation } & \multirow{2}{*}{$\begin{array}{l}\text { sPTD } \\
\mathbf{n} \\
\end{array}$} & \multicolumn{3}{|c|}{ Unadjusted } & \multicolumn{3}{|c|}{ Adjusted $^{1}$} \\
\hline & & & HR & (CI) & $\mathbf{p}$ & HR & (CI) & $p$ \\
\hline \multirow[t]{4}{*}{ All } & >8 w preconception & 478 & 1.17 & $(1.06 ; 1.30)$ & 0.003 & 1.17 & $(1.04 ; 1.32)$ & 0.01 \\
\hline & 0-8 w preconception & 648 & 1.01 & $(0.92 ; 1.12)$ & 0.80 & 1.01 & $(0.90 ; 1.13)$ & 0.84 \\
\hline & 1st trimester & 1326 & 0.94 & $(0.84 ; 1.05)$ & 0.26 & 0.89 & $(0.79 ; 1.00)$ & 0.05 \\
\hline & 2nd trimester & 869 & 1.10 & $(1.00 ; 1.21)$ & 0.04 & 1.08 & $(0.98 ; 1.19)$ & 0.11 \\
\hline \multirow[t]{4}{*}{ Early } & >8 w preconception & 108 & 1.49 & $(1.19 ; 1.88)$ & 0.001 & 1.51 & $(1.16 ; 1.97)$ & 0.002 \\
\hline & 0-8 w preconception & 133 & 1.15 & $(0.92 ; 1.43)$ & 0.23 & 1.03 & $(0.80 ; 1.34)$ & 0.81 \\
\hline & 1st trimester & 262 & 1.11 & $(0.85 ; 1.44)$ & 0.45 & 0.99 & $(0.74 ; 1.32)$ & 0.95 \\
\hline & 2nd trimester & 173 & 1.21 & $(0.97 ; 1.49)$ & 0.09 & 1.12 & $(0.89 ; 1.39)$ & 0.34 \\
\hline \multirow[t]{4}{*}{ Late } & >8 w preconception & 370 & 1.10 & $(0.98 ; 1.24)$ & 0.10 & 1.10 & $(0.97 ; 1.26)$ & 0.15 \\
\hline & 0-8 w preconception & 515 & 0.98 & $(0.88 ; 1.09)$ & 0.69 & 1.00 & $(0.88 ; 1.13)$ & 0.94 \\
\hline & 1st trimester & 1064 & 0.91 & $(0.81 ; 1.03)$ & 0.13 & 0.87 & $(0.76 ; 1.00)$ & 0.04 \\
\hline & 2nd trimester & 696 & 1.08 & $(0.98 ; 1.20)$ & 0.13 & 1.08 & $(0.97 ; 1.20)$ & 0.17 \\
\hline
\end{tabular}

Folic acid supplementation at different times (Q1 and Q3 data) and hazard ratios (HR) for spontaneous PTD $\left(n=1.755\right.$ for $22^{+0}-36^{+6}$ weeks, $n=334$ for early $\left(22^{+0}-33^{+6}\right.$ weeks), $n=1,421$ for late $\left(34^{+0}-36^{+6}\right.$ weeks)) as compared to no intake at that time of pregnancy. Cox regression for 66,014 participants in the Norwegian Mother and Child Cohort Study (2002 - 2009). latrogenic deliveries have been censored in the regression model.

${ }^{1}$ Cox regression, adjusted for maternal age, prepregnancy BMI, parity, history of PTD and spontaneous abortion, child's sex, smoking habits and alcohol consumption during pregnancy, maternal education, marital status, household income, energy intake and dietary folate intake. Mutual adjustment for folic acid supplementation at other time points. 
socioeconomic and life-style parameters as well as obstetric anamnesis.

Associations with the early start of supplementation should be studied with particular caution. The early start of folic acid supplementation might partially identify a group of women with a history of adverse pregnancy outcomes who want to optimize conditions for their current pregnancy. As presented in Table 1, women who had previously experienced spontaneous abortions were more likely to initiate folic acid supplementation early in their subsequent pregnancies. However, the same association of the early initiation of folic acid supplementation and spontaneous PTD was found in women being pregnant the first time. Folic acid supplementation starting more than 8 weeks prior to conception might characterize women who planned a pregnancy but did not become pregnant during their first 2 cycles, thus constituting a subgroup of women with suboptimal fertility [37]. The same association of the early start of supplementation was found in the group of women that became pregnant within the first month. Women who choose to start early with folic acid supplementation might be distinguished by some other characteristic that could be the causal link to spontaneous preterm delivery so that we cannot exclude confounding.

In addition to the amount of folic acid, the composition of supplements is another point of discussion. In some countries like Greece and Norway, commonly used supplements contain folic acid and/or iron only [20]. In other countries, folic acid is mainly consumed in the form of multivitamins, making it difficult to differentiate the effects of multivitamin use and folic acid supplementation $[21,37,43,50]$. Vitamins other than folic acid might explain the association between multivitamin use and PTD. Catov et al. found that in the Danish birth cohort, multivitamin use was associated with modestly decreased PTD rates, while there was no association with folic acid supplementation [39]. As seen from Figure 1, vitamin A consumption (as a proxy for multivitamin supplementation) differed considerably from folic acid supplementation. However, the MoBa FFQ allowed us to calculate folic acid separately from other supplements, and adjusting for vitamin A consumption did not change the results for preconceptional folic acid supplementation.

Apart from the amount, timing and composition of folate exposure, differences in the definition of pregnancy outcomes hinder comparability. Most studies defined PTD as delivery at $<37^{+0}$ weeks of gestation without indicating the range of gestational age. This information might be important, especially if the risk of early PTD is found to be associated with folate status, as suggested by this study and that of Bukowski et al. [21]. Although PTD is a heterogeneous pregnancy outcome with distinct etiologies for different subgroups [26], not all studies analyzed clearly defined subgroups such as spontaneous PTD $[20,21,39,42,49,55]$.

\section{Strengths and weaknesses}

With a sample size of 66,014 pregnancies, this was a wellpowered study for investigating the association of folate intake and spontaneous PTD. Due to the large study sample, there were 1,755 cases defined as spontaneous PTD and 334 and 1,421 cases in the subgroups of early and late spontaneous PTD, respectively. The estimation of the gestational length by the second-trimester ultrasounds and the definition of a clear PTD phenotype - spontaneous onset of delivery between $22^{+0}$ and $36^{+6}$ weeks of gestation distinguish this study.

The MoBa participation rate is $38.5 \%$, and a demographic comparison with the MBRN in 2002 showed that single women and women $<25 \mathrm{y}$ of age are underrepresented in MoBa. Regarding PTD (7.2\% in MoBa and $7.7 \%$ in MBRN), the differences are minor, and even the sub-group composition is similar to the distribution in the total population, with spontaneous PTD accounting for $42 \%$ of all PTD [15]. Although the low participation in MoBa influences prevalence estimates somewhat, such non-representativeness does not appear to affect exposure-outcome associations [56,57].

The assessment of folate from both the diet and supplements is a major strength of this study. Although all dietary assessment methods have limitations, the MoBa FFQ has been extensively validated in a sub-population of 119 MoBa participants using a 4-day weighed food diary and biological markers in the blood and urine as reference measures [58]. The dietary supplement use was evaluated specifically. The total folate intake by the FFQ showed good agreement with the folate intake detailed by the food diary and was significantly reflected by the serum folate concentrations [33]. In a subsample of an earlier MoBa version (2934 singleton pregnancies), Nilsen et al. did not find any significant associations of dietary folate intake, folic acid supplementation or plasma folate with PTD. This study also reported good agreement between the folate intake (dietary and supplements) by the MoBa FFQ and plasma folate concentration ( $\mathrm{r}=0.44, \mathrm{CI}: 0.41-0.47)$ [40]. As the relevant window of susceptibility for folate effects regarding pregnancy outcomes other than NTD is not yet known, the assessment of folate intake at different time points is a further strength of this study. The prospective design ensured that the women's answers were not influenced by their knowledge of pregnancy outcomes.

\section{Conclusions}

The overall amount of dietary folate and supplemental folic acid intake (during the first half of pregnancy) in 66,014 singleton pregnancies from the Norwegian Mother and Child Cohort Study was not associated with decreased or increased risk of spontaneous PTD, at least not at the relatively low intake levels of dietary folate (median 
$157 \mu \mathrm{g} / \mathrm{d}$ corrected for bio-availability, uncorrected $262 \mu \mathrm{g} / \mathrm{d}$ ) and supplemental folic acid (median $143 \mu \mathrm{g} / \mathrm{d}$ ) in this healthy study population.

The initiation of folic acid supplementation more than 8 weeks prior to conception was associated with an increased risk for overall and early spontaneous PTD in both the overall analyses and in the strata of women with low dietary folate intake.

Even if MoBa allows adjustment for a variety of confounders, the presence of residual confounding cannot be ruled out. Furthermore, our results require careful investigation regarding dosage and timing of folic acid supplementation, such as in the form of an RCT, before discussing a change of the current guidelines.

\section{Additional files}

Additional file 1: Table S1. Folate intake according to official recommendations and risk of spontaneous preterm delivery (PTD).

Additional file 2: Figure S1a. Initiation of preconceptional folic acid supplementation and risk of spontaneous PTD. Initiation of preconceptional folic acid supplementation (Q1 data) and cumulative risk of spontaneous PTD $\left(22^{+0}-36^{+6}\right.$ weeks, $\left.n=1,755\right)$. Cox regression for 66,014 participants in the Norwegian Mother and Child Cohort Study (2002 - 2009), adjusted for maternal age, prepregnancy BMI, parity, history of PTD and spontaneous abortion, child's sex, smoking habits and alcohol consumption during pregnancy, maternal education, marital status, household income, energy intake and dietary folate intake. latrogenic deliveries have been censored in the regression model.

Additional file 3: Figure S1b. Initiation of preconceptional folic acid supplementation and risk of early spontaneous PTD. Initiation of preconceptional folic acid supplementation (Q1 data) and cumulative risk of early spontaneous PTD $\left(22^{+0}-33^{+6}\right.$ weeks, $\left.n=334\right)$. Cox regression for 66,014 participants in the Norwegian Mother and Child Cohort Study (2002 - 2009), adjusted for maternal age, prepregnancy BMI, parity, history of PTD and spontaneous abortion, child's sex, smoking habits and alcohol consumption during pregnancy, maternal education, marital status, household income, energy intake and dietary folate intake. latrogenic deliveries have been censored in the regression model.

Additional file 4: Table S2. Initiation of preconceptional folic acid supplementation and risk of spontaneous preterm delivery (SPTD), depending on dietary folate intake.

\section{Abbreviations}

BMI: Body mass index; Cl: Confidence interval; FFQ: Food frequency questionnaire; HR: Hazard ratio; IQR: Interquartile range; MoBa: The Norwegian Mother and Child Cohort Study; MBRN: Medical birth registry of Norway; NOK: Norwegian crowns, currency; NTD: Neural tube defect; PTD: Preterm delivery; Q1: Q3, Questionnaire 1, 3; RCT: Randomized controlled trial; WHO: World health organization.

\section{Competing interests}

The authors declare that they have no competing interests.

\section{Authors' contributions}

All authors planned the study. VS, JB and SN analyzed the data. VS, RM, SM, BJ selected preterm deliveries. MH calculated on folate intake from Q2. All authors contributed with interpretation of results and writing of the paper. All authors have read and approved the final manuscript.

\section{Acknowledgments}

We are grateful to all families in Norway who are participating in this ongoing cohort study.
Statement of financial support: This work was supported by grants from the Norwegian Research Council (FUGE 183220/S10, FRIMEDKLI-05 ES236011), the Swedish Medical Society (SLS 2008-21198) and Swedish government grants to researchers in public health service (ALFGBG-2863, ALFGBG-11522, ALF-ST FoUU/Sahlgrenska University Hospital, Gothenburg), Stiftelsen Sigurd och Elsa Goljes Minne (LA2011-0489). The funders had no role in study design, data collection and analysis, decision to publish, or preparation of the manuscript.

\section{Author details}

${ }^{1}$ Department of Obstetrics and Gynaecology, Sahlgrenska Academy, Sahlgrenska University Hospital/Östra, Göteborg SE-416 85, Sweden. ${ }^{2}$ Department of Genes and Environment, Division of Epidemiology, Norwegian Institute of Public Health, Nydalen, P.O. Box 4404, Oslo NO-0403, Norway. 'Department of Obstetrics and Gynecology, Women and Children's Division, Oslo University Hospital, Nydalen, P.O. Box 4950, Oslo NO-0424, Norway. ${ }^{4}$ Department of Exposure and Risk Assessment, Division of Environmental Medicine, Norwegian Institute of Public Health, Nydalen, P.O. Box 4403, Oslo NO-0403, Norway. ${ }^{5}$ Department of Global Public Health and Primary Care, University of Bergen, Bergen NO-5018, Norway. ${ }^{6}$ Division of Epidemiology, Norwegian Institute of Public Health, P.O. Box 4403, Oslo NO-0403, Norway. ${ }^{7}$ Norwegian Institute of Public Health and University of Bergen, Kalfarveien 31, Bergen NO-5018, Norway. ${ }^{8}$ Mathematical Sciences, Chalmers University of Technology, Göteborg SE-412 96, Sweden.

Received: 6 June 2014 Accepted: 16 October 2014 Published online: 02 November 2014

\section{References}

1. Tamura T, Picciano MF: Folate and human reproduction. Am J Clin Nutr 2006, 83(5):993-1016.

2. Nordic Council of Ministers: Folate. In Nordic Nutrition Recommendations 2004 Integrating nutrition and physical activity. Copenhagen: Norden; 2004:287-296

3. World Health Organization; Food and Agricultural Organization of the United Nations: Folate and Folic acid. In Vitamin and mineral requirements in human nutrition. Rome: FAO; 2004:53-62.

4. Scholl TO, Johnson WG: Folic acid: influence on the outcome of pregnancy. Am J Clin Nutr 2000, 71(5 Suppl):1295S-1303S.

5. Israels MC, Da Cunha FA: Megaloblastic anaemia of pregnancy. Lancet 1952, 2(6727):214-215.

6. Czeizel AE, Dudas I, Metneki J: Pregnancy outcomes in a randomised controlled trial of periconceptional multivitamin supplementation. Final report. Arch Gynecol Obstet 1994, 255(3):131-139.

7. Czeizel $A E$, Dudas I: Prevention of the first occurrence of neural-tube defects by periconceptional vitamin supplementation. N Engl J Med 1992, 327(26):1832-1835.

8. MRC Vitamin Study Research Group: Prevention of neural tube defects: results of the Medical Research Council Vitamin Study. Lancet 1991, 338(8760):131-137.

9. Shaw GM, Carmichael SL, Nelson V, Selvin S, Schaffer DM: Occurrence of low birthweight and preterm delivery among California infants before and after compulsory food fortification with folic acid. Public Health Rep 2004, 119(2):170-173.

10. De Bree A, Van Dusseldorp M, Brouwer IA, van het Hof KH, SteegersTheunissen RP: Folate intake in Europe: recommended, actual and desired intake. Eur J Clin Nutr 1997, 51(10):643-660.

11. Kostholdsråd gravide (Dietary recommendation for pregnant women, in Norwegian) [http://www.helsedirektoratet.no/folkehelse/ernering/kostholdsrad/ gravide/Sider/default.aspx]

12. WHO Expert Committee: The prevention of perinatal mortality and morbidity. Report of a WHO Expert Committee. World Health Organ Tech Rep Ser 1970, 457:1-60.

13. Moster D, Lie RT, Markestad T: Long-term medical and social consequences of preterm birth. N Engl J Med 2008, 359(3):262-273.

14. Bryce J, Boschi-Pinto C, Shibuya K, Black RE: WHO estimates of the causes of death in children. Lancet 2005, 365(9465):1147-1152.

15. Magnus P, Irgens LM, Haug K, Nystad W, Skjaerven R, Stoltenberg C: Cohort profile: the Norwegian mother and child cohort study (MoBa). Int J Epidemiol 2006, 35(5):1146-1150. 
16. Lockwood CJ: Predicting premature delivery-no easy task. N Engl J Med 2002, 346(4):282-284.

17. Dodd JM, Flenady VJ, Cincotta R, Crowther CA: Progesterone for the prevention of preterm birth: a systematic review. Obstet Gynecol 2008, 112(1):127-134.

18. Romero R, Nicolaides K, Conde-Agudelo A, Tabor A, O'Brien JM, Cetingoz E, Da Fonseca E, Creasy GW, Klein K, Rode L, Soma-Pillay P, Fusey S, Cam C, Alfirevic Z, Hassan SS: Vaginal progesterone in women with an asymptomatic sonographic short cervix in the midtrimester decreases preterm delivery and neonatal morbidity: a systematic review and metaanalysis of individual patient data. Am J Obstet Gynecol 2012, 206(2):124 e121-119.

19. Li Z, Ye R, Zhang L, Li H, Liu J, Ren A: Periconceptional folic acid supplementation and the risk of preterm births in China: a large prospective cohort study. Int J Epidemiol 2014, 43(4):1132-1139.

20. Papadopoulou E, Stratakis N, Roumeliotaki T, Sarri K, Merlo DF, Kogevinas M, Chatzi L: The effect of high doses of folic acid and iron supplementation in early-to-mid pregnancy on prematurity and fetal growth retardation: the mother-child cohort study in Crete, Greece (Rhea study). Eur J Nutr 2013, 52(1):327-336.

21. Bukowski R, Malone FD, Porter FT, Nyberg DA, Comstock CH, Hankins GD, Eddleman K, Gross SJ, Dugoff L, Craigo SD, Timor-Tritsch IE, Carr SR, Wolfe HM, D'Alton ME: Preconceptional folate supplementation and the risk of spontaneous preterm birth: a cohort study. PLOS Med 2009, 6(5):e1000061.

22. Czeizel AE, Puho EH, Langmar Z, Acs N, Banhidy F: Possible association of folic acid supplementation during pregnancy with reduction of preterm birth: a population-based study. Eur J Obstet Gynecol Reprod Biol 2010, 148(2):135-140.

23. Lassi ZS, Salam RA, Haider BA, Bhutta ZA: Folic acid supplementation during pregnancy for maternal health and pregnancy outcomes. Cochrane Database Syst Rev 2013, 3:CD006896.

24. Charles DH, Ness AR, Campbell D, Smith GD, Whitley E, Hall MH: Folic acid supplements in pregnancy and birth outcome: re-analysis of a large randomised controlled trial and update of Cochrane review. Paediatr Perinat Epidemiol 2005, 19(2):112-124.

25. Fekete K, Berti C, Trovato M, Lohner S, Dullemeijer C, Souverein OW, Cetin I, Decsi T: Effect of folate intake on health outcomes in pregnancy: a systematic review and meta-analysis on birth weight, placental weight and length of gestation. Nutr J 2012, 11(1):75.

26. Pennell CE, Jacobsson B, Williams SM, Buus RM, Muglia L, Dolan SM, Morken NH, Ozcelik H, Lye SJ, Relton C: Genetic epidemiologic studies of preterm birth: guidelines for research. Am J Obstet Gynecol 2007, 196(2):107-118.

27. Mantovani E, Filippini F, Bortolus R, Franchi M: Folic acid supplementation and preterm birth: results from observational studies. Biomed Res Int 2014, 2014:481914

28. Norwegian Mother and Child Study. [http://www.fhi.no/eway/default.aspx? pid=240\&trg=Main_6664\&Main 6664=6894:0:25,7372:1:0:0: 0:0

29. Irgens LM: The Medical Birth Registry of Norway. Epidemiological research and surveillance throughout 30 years. Acta Obstet Gynecol Scand 2000, 79(6):435-439.

30. Meltzer HM, Brantsaeter AL, Ydersbond TA, Alexander J, Haugen M: Methodological challenges when monitoring the diet of pregnant women in a large study: experiences from the Norwegian Mother and Child Cohort Study (MoBa). Matern Child Nutr 2008, 4(1):14-27.

31. FoodCalc. [http://www.ibt.ku.dk/jesper/FoodCalc/Default.htm]

32. Rimestad AH, Borgejordet A, Vesterhus KN, Sygnestveit K, Løken EB, Trygg K, Pollestad ML, Lund-Larsen K, Omholt-Jensen G, Nordbotten A: Matvaretabellen (The Norwegian Food Table, in Norwegian). University of Oslo: Norwegian Food Safety Authority; Norwegian Directorate of Health; Department of Nutrition; 2001.

33. Brantsaeter AL, Haugen M, Hagve TA, Aksnes L, Rasmussen SE, Julshamn K, Alexander J, Meltzer HM: Self-reported dietary supplement use is confirmed by biological markers in the Norwegian Mother and Child Cohort Study (MoBa). Ann Nutr Metab 2007, 51(2):146-154

34. Haugen M, Brantsaeter AL, Alexander J, Meltzer HM: Dietary supplements contribute substantially to the total nutrient intake in pregnant Norwegian women. Ann Nutr Metab 2008, 52(4):272-280.

35. FAO/WHO Expert Consultation: Requirements of Vitamin A, Iron, Folate and Vitamin B12 Report of a Joint Fao/Who Expert Consultation (Fao Fisheries
Report). Rome, Lanham, MD: Food and Agriculture Organization of the United Nations; 1988.

36. Grambsch PM, Therneau TM: Proportional hazards tests and diagnostics based on weighted residualsProportional hazards tests and diagnostics based on weighted residuals. Biometrika 1994, 81:515-526.

37. Callaway L, Colditz PB, Fisk NM: Folic acid supplementation and spontaneous preterm birth: adding grist to the mill? PLOS Med 2009, 6(5):e1000077.

38. Alwan NA, Greenwood DC, Simpson NA, McArdle HJ, Cade JE: The relationship between dietary supplement use in late pregnancy and birth outcomes: a cohort study in British women. BJOG 2010, 117(7):821-829.

39. Catov JM, Bodnar LM, Olsen J, Olsen S, Nohr EA: Periconceptional multivitamin use and risk of preterm or small-for-gestational-age births in the Danish National Birth Cohort. Am J Clin Nutr 2011, 94(3):906-912

40. Nilsen RM, Vollset SE, Monsen AL, Ulvik A, Haugen M, Meltzer HM, Magnus $P$, Ueland PM: Infant birth size is not associated with maternal intake and status of folate during the second trimester in Norwegian pregnant women. J Nutr 2010, 140(3):572-579.

41. Timmermans S, Jaddoe WW, Hofman A, Steegers-Theunissen RP, Steegers EA: Periconception folic acid supplementation, fetal growth and the risks of low birth weight and preterm birth: the Generation R Study. Br J Nutr 2009, 102(5):777-785.

42. Dunlop AL, Taylor RN, Tangpricha V, Fortunato S, Menon R: Maternal micronutrient status and preterm versus term birth for black and white US women. Reprod Sci 2012, 19(9):939-948.

43. Shaw GM, Carmichael SL, Yang W, Siega-Riz AM: Periconceptional intake of folic acid and food folate and risks of preterm delivery. Am J Perinatol 2011, 28(10):747-752.

44. Fleming AF, Martin JD, Stenhouse NS: Pregnancy anaemia, iron and folate deficiency in Western Australia. Med J Aust 1974, 2(13):479-484.

45. Fletcher J, Gurr A, Fellingham FR, Prankerd TA, Brant HA, Menzies DN: The value of folic acid supplements in pregnancy. J Obstet Gynaecol Br Commonw 1971, 78(9):781-785

46. Baumslag N, Edelstein T, Metz J: Reduction of incidence of prematurity by folic acid supplementation in pregnancy. Br Med J 1970, 1(5687):16-17.

47. Rolschau J, Kristoffersen K, Ulrich M, Grinsted P, Schaumburg E, Foged N: The influence of folic acid supplement on the outcome of pregnancies in the county of Funen in Denmark. Part I. Eur J Obstet Gynecol Reprod Biol 1999, 87(2):105-110. discussion 103-104.

48. Scholl TO, Hediger ML, Bendich A, Schall II, Smith WK, Krueger PM: Use of multivitamin/mineral prenatal supplements: influence on the outcome of pregnancy. Am J Epidemiol 1997, 146(2):134-141.

49. Siega-Riz AM, Savitz DA, Zeisel SH, Thorp JM, Herring A: Second trimester folate status and preterm birth. Am J Obstet Gynecol 2004, 191(6):1851-1857.

50. Furness DL, Yasin N, Dekker GA, Thompson SD, Roberts CT: Maternal red blood cell folate concentration at 10-12 weeks gestation and pregnancy outcome. J Matern Fetal Neonatal Med 2012, 25(8):1423-1427.

51. Scholl TO, Hediger ML, Schall $\mathrm{Jl}$, Khoo CS, Fischer RL: Dietary and serum folate: their influence on the outcome of pregnancy. Am J Clin Nutr 1996, 63(4):520-525

52. Bailey RL, Dodd KW, Gahche JJ, Dwyer JT, McDowell MA, Yetley EA, Sempos CA, Burt VL, Radimer KL, Picciano MF: Total folate and folic acid intake from foods and dietary supplements in the United States: 2003-2006. Am J Clin Nutr 2010, 91(1):231-237.

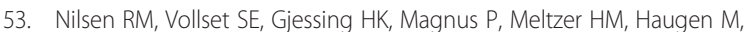
Ueland PM: Patterns and predictors of folic acid supplement use among pregnant women: the Norwegian mother and child cohort study. Am J Clin Nutr 2006, 84(5):1134-1141.

54. Nilsen RM, Mastroiacovo P, Gunnes N, Alsaker ER, Bjorke-Monsen AL, Eussen SJ, Haugen M, Johannessen A, Meltzer HM, Stoltenberg C, Ueland PM, Vollset SE: Folic acid supplementation and interpregnancy interval. Paediatr Perinat Epidemiol 2014, 28(3):270-274.

55. Bergen $N E$, Jaddoe $W W$, Timmermans $S$, Hofman A, Lindemans J, Russcher $H_{\text {, }}$ Raat $\mathrm{H}$, Steegers-Theunissen RP, Steegers EA: Homocysteine and folate concentrations in early pregnancy and the risk of adverse pregnancy outcomes: the Generation R Study. BJOG 2012, 119(6):739-751.

56. Nilsen RM, Suren P, Gunnes N, Alsaker ER, Bresnahan M, Hirtz D, Hornig M, Lie KK, Lipkin WI, Reichborn-Kjennerud T, Roth C, Schjolberg S, Smith GD, Susser E, Vollset SE, Oyen AS, Magnus P, Stoltenberg C: Analysis of selfselection bias in a population-based cohort study of autism spectrum disorders. Paediatr Perinat Epidemiol 2013, 27(6):553-563. 
57. Nilsen RM, Vollset SE, Gjessing HK, Skjaerven R, Melve KK, Schreuder P, Alsaker ER, Haug K, Daltveit AK, Magnus P: Self-selection and bias in a large prospective pregnancy cohort in Norway. Paediatr Perinat Epidemiol 2009, 23(6):597-608

58. Brantsaeter AL, Haugen M, Alexander J, Meltzer HM: Validity of a new food frequency questionnaire for pregnant women in the Norwegian Mother and Child Cohort Study (MoBa). Matern Child Nutr 2008, 4(1):28-43.

doi:10.1186/s12884-014-0375-1

Cite this article as: Sengpiel et al:: Folic acid supplementation, dietary

folate intake during pregnancy and risk for spontaneous preterm

delivery: a prospective observational cohort study. BMC Pregnancy and

Childbirth 2014 14:375.

\section{Submit your next manuscript to BioMed Central and take full advantage of:}

- Convenient online submission

- Thorough peer review

- No space constraints or color figure charges

- Immediate publication on acceptance

- Inclusion in PubMed, CAS, Scopus and Google Scholar

- Research which is freely available for redistribution 